\title{
Evaluation of synuclein- $\gamma$ levels by novel monoclonal antibody in saliva and cancer tissues from oral squamous cell carcinoma patients
}

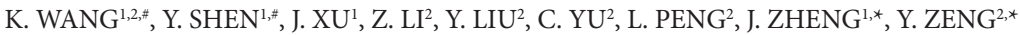 \\ ${ }^{1}$ Department of Stomatology, The First Affiliated Hospital, School of Medicine, Shihezi University, Shihezi, Xinjiang, China; ${ }^{2}$ Key Laboratory of \\ Xinjiang Endemic and Ethnic Disease, School of Medicine, Shihezi University, Shihezi, Xinjiang, China \\ *Correspondence: zengyan910@gmail.com; haohaoay@yeah.net \\ "Contributed equally to this work.
}

Received June 19, 2019 / Accepted November 6, 2019

\begin{abstract}
The clinical value of synuclein- $\gamma$ (SNCG) in oral squamous cell carcinoma (OSCC) was evaluated by detecting the expression of SNCG in saliva and tissues and its correlation with clinicopathological parameters (age, gender, ethnicity, degree of differentiation, clinical stage, and lymph node metastasis). Salivary samples were collected from 79 patients with OSCC, 31 patients with oral premalignant lesions (OPMLs), such as oral lichen planus, oral leukoplakia, and erythema, and 80 controls, and levels of SNCG in salivary samples were determined by enzyme-linked immunosorbent assay (ELISA). Tissue expression in formalin-fixed tissue biopsies of 94 cases of OSCC and 30 adjacent normal tissues was analyzed by immunohistochemistry (IHC) using an antibody against SNCG. The results showed that the salivary levels of SNCG in patients with OSCC and OPMLs were significantly higher than those detected in the control group $(\mathrm{p}<0.001)$. The immunohistochemical results showed that SNCG was highly expressed in tumor cells of OSCC patients, with low expression in the adjacent normal epithelium $(p<0.001, O R=6.074)$. Salivary SNCG level correlated with differentiation $(p=0.022)$. Besides, the expression of SNCG in OSCC tissues was also significantly associated with differentiation $(\mathrm{p}<0.001)$.
\end{abstract}

Key words: oral squamous cell carcinoma, synuclein- $\gamma$, saliva, oral premalignant lesions

Oral squamous cell carcinoma (OSCC) is a subset of head and neck squamous cell carcinoma and constitutes about $94 \%$ of all oral malignant tumors [1]. The position of this disease occurs in the mouth and can be found in the gingiva, hard palate, tongue, buccal mucosa, lips, and other oral locations. The incidence of OSCC is related to a variety of risk factors, including genetic susceptibility, environmental factors, lifestyle, diet and other factors, such as chewing of betel quid, areca nut, and their substitutes, e.g. gutka [2]. In addition, some oral mucosal lesions, such as oral leukoplakia, oral submucous fibrosis, and oral lichen planus are also considered as precancerous lesions of OSCC [3]. Moreover, long-term inflammation or mechanical damage to the oral mucosa, or irritation caused by long-term unhealed ulcers are also causes of OSCC [4]. Despite advances in therapies, the overall 5-year survival rate has remained unchanged during the past decades, mainly due to delayed diagnosis, underdiagnosis or misdiagnosis [5]. Hence, the data demonstrate the importance of early diagnosis and indirectly show that identifying diagnostic biomarkers is extremely urgent.
Biomarkers can be detected in serum, saliva, and tissue using convenient and rapid methods. Gradually, noninvasive methods are becoming the first choice for most biopsies, and it is apparent that saliva has an advantage in detecting OSCC, thus finding sensitive biomarkers in the saliva is attracting attention among scientists and doctors. Saliva and oral malignancies are closely related. Levels of over 100 salivary biomarkers for oral malignancies, including Endothelin-1, IL-1 $\beta$, IL-8, glycoprotein M2BP (Mac-2-binding protein), CD59, myeloid-related protein 14 (MRP14) and matrix metalloproteinase (MMP)-9 have been identified as changing significantly in OSCC patients, but these markers exhibited a low value to detect OSCC [6]. Therefore, we would like to explore a more ideal marker for OSCC in the present study.

Currently, synuclein- $\gamma$ (SNCG), found in both neurodegenerative diseases and cancer, is attracting public attention. It is reported that high expression of SNCG is found in most tumor stages, for example in breast cancer [7] and colorectal cancer [8]. Previous studies have shown that SNCG expression significantly stimulates the proliferation, invasion, and 
metastasis of breast cancer cells [9]. SNCG is overexpressed in various tumor tissues and predicts adverse outcomes in breast, colon, and pancreatic cancer patients [10]. According to several reports, all OSCC cells show detectable SNCG expression at the mRNA and protein levels [11]. SNCG is actively secreted by cancer cells and extracellular SNCG promotes malignant phenotypes of cancer cells.

In this study, we analyzed SNCG expression in tissue and saliva samples from three groups: patients with OSCC, those with precancerous lesions, and healthy controls, we also explored the relationship between the expression of SNCG and OSCC diagnosis and prognosis, to evaluate whether SNCG could be a valuable biomarker for the diagnosis and prognosis in OSCC.

\section{Materials and methods}

Study population. The Ethics Committee of the First Affiliated Hospital of the Medical College, Shihezi University approved this study. All tissues, as well as salivary samples, were from our hospital and the First Affiliated Hospital of Xinjiang Medical University. 94 surgically resected specimens including 30 cases of matched adjacent normal tissues were taken from OSCC patients who underwent surgery between 2010 and 2018 [12]. The diagnosis of OSCC was confirmed by histopathology and staging according to the UICC TNM classification and comprised 74 Stage I/II tumors and 20 Stage III/IV tumors. The presence of lymph node metastases was identified by histological examination. None of the patients received preoperative chemotherapy or radiotherapy and all were subjected to radical surgery. Salivary samples were obtained from 79 patients diagnosed with OSCC, 31 cases of OPMLs and 80 healthy persons between 2013 and 2018. Out of total 31 cases of OPML, $48.4 \%(n=15)$ were leukoplakia followed by lichen planus $(35.5 \%, n=11)$ and oral submucous fibrosis $(16.1 \%, n=5)$. The controls were gender and age-matched subjects enrolled at the same time as the OSCC patients, controls were generally healthy individuals without any systemic disease, cancer or inflammatory oral disease, exclusion criteria as described previously [13]. Salivary samples were collected before any surgical procedures or chemotherapy protocols. All subjects were informed about the research and agreed to participate in the study by signing the free and informed consent form. Clinical data, such as sex, age, cell differentiation, tumor stage, lymph node metastasis, and clinical TNM stage were obtained from medical records.

Material collection. Saliva was collected with the consent of the patients. Subjects were asked to rinse out their mouth with water at least 5 min prior to saliva collection [13]. The collection procedure was as follows: 1 to $2 \mathrm{ml}$ of naturally-secreted saliva was obtained in a collection tube, then the sample was centrifuged at $1000 \times \mathrm{g}$ for $2 \mathrm{~min}$ at room temperature (RT) and the supernatant was transferred to a sterile sample tube and mixed with protease inhibitor [14]. All salivary samples were frozen at $-80^{\circ} \mathrm{C}$ until the application.

Enzyme-linked immunosorbent assay (ELISA). The level of salivary SNCG was quantified using the ELISA and an SNCG standard solution was purified from MCF7-SNCG cells, as described [15]. A $50 \mu \mathrm{l}$ aliquot of each saliva sample or $50 \mu \mathrm{l}$ of SNCG standard solution was combined with $50 \mu \mathrm{l}$ horseradish peroxidase-labeled anti-SNCG monoclonal antibody (MAb) no.1 (Peking University Cancer Hospital and Institute) in assay buffer - $10 \mathrm{mM}$ phosphate-buffered saline (PBS), $0.1 \%$ Tween-20, and 10\% fetal calf serum in microtiter plates coated with another anti-SNCG MAb no.42 (Peking University Cancer Hospital and Institute) [11]. The plates were incubated for $3 \mathrm{~h}$ at RT with shaking, then washed and $100 \mu \mathrm{l} /$ well of TMB substrate solution was added to all wells, after which the plates were kept at RT for $15 \mathrm{~min}$. Stop solution was added at $100 \mu \mathrm{l} /$ well to stop the enzyme reaction, and the absorbance was read at $450 \mathrm{~nm}$ using a spectrophotometer. The SNCG level in the sample was calculated according to the prepared standard curve.

Immunohistochemical (IHC) staining. Paraffinembedded tissue samples were serially sectioned at $4 \mu \mathrm{m}$. After baking at $60^{\circ} \mathrm{C}$ overnight, the sections were dewaxed and rehydrated through xylene and an alcohol series, respectively. Blocking endogenous peroxidase was performed by incubation in 3\% hydrogen peroxide for $10 \mathrm{~min}$ at RT. Then, thermal repair of the antigen was performed by microwave heating in EDTA. After blocking with $10 \%$ goat serum, the sections were incubated with anti-SNCG MAb no.1 for $2 \mathrm{~h}$ at RT, tissue sections were then washed in PBS and incubated with secondary antibody from the Envision ${ }^{\mathrm{TM}}$ kit (Dako Cytomation, Cambridge, UK) for $45 \mathrm{~min}$ at RT. Subsequently, immunoreactivity was visualized with diaminobenzidine (Sigma-Aldrich, St. Louis, USA), and the sections were counterstained with hematoxylin. Normal mouse IgG was used as a negative control.

Evaluation of IHC staining. Staining was performed as described previously [16]. The number of brown-yellow stained granules in the cytoplasm of OSCC cells $<10 \%$ was scored as 0 , and the number of immunostained cells $>10 \%$ was scored as 1; according to the intensity of staining, the cells were further divided into,,++++++ , and scored as 1 , 2,3 , respectively. A total score $<3$ was categorized as SNCG negative by immunohistochemical staining, while a total score $\geq 3$ was classified as SNCG positive by immunohistochemical staining.

Statistical analysis. All statistical analyses were performed using SPSS version 20.0 (IBM, Armonk, USA), and all results are presented as the mean \pm standard deviation (SD). One-way ANOVA test was used to evaluate the significance of differences between groups. Associations between the clinicopathological characteristics of the patients and SNCG expression levels were analyzed using the chi-square test or unpaired Student's t-test. Graphs were plotted using GraphPad Prism for Windows ver.5.0 
(GraphPad Software, San Diego, USA). Receiver operator characteristic (ROC) curve analysis was performed, and the best cut-off point was determined by the Youden index, the best cut-off value was defined as the test result with the highest sensitivity and specificity and that lied closest to the left upper corner of the curve. The area under the curve presented a direct measure of the diagnostic accuracy of the test. For all the tests, $\mathrm{p}<0.05$ was considered statistically significant.

\section{Results}

Expression of salivary SNCG levels in OSCC, precancerous lesions, and healthy control groups. The salivary levels of SNCG in OSCC and OPMLs in comparison to control subjects are shown in Figure 1. Salivary levels of SNCG in OSCC patients were significantly higher than those in the control group $(p<0.05)$. Additionally, salivary levels of SNCG in OPML patients were also significantly higher than those in the control group ( $\mathrm{p}<0.05$, OSCC; median: 1.420 , range: $0.490-6.660$, OPMLs; median: 1.293 , range: $0.850-$ 4.750). Differences in saliva SNCG contents between OSCC and OPML groups were not statistically significant ( $\mathrm{p}>0.05)$. Table 1 compares the SNCG contents of saliva for all study groups.

Association of salivary SNCG levels with clinical indexes. Relationships between salivary SNCG levels in OSCC patients and clinicopathological characteristics, including age, sex, ethnicity, degree of differentiation, clinical stage, and lymph node metastasis $[17,18]$, are shown in Table 2. Differences between salivary SNCG expression and degree of differentiation were statistically significant $(\mathrm{p}<0.05)$. However, differences between salivary SNCG content and other clinical parameters, including age, sex, ethnicity, clinical stage, and lymph node metastasis, were not statistically significant ( $\mathrm{p}>0.05)$.

Expression of SNCG in OSCC and the adjacent normal tissues. We analyzed the expression of SNCG, which contained 94 cases of OSCC tissues and 30 cases adjacent normal tissues. SNCG is mainly expressed in the cytoplasm, which is stained brownish yellow (Figure 2). The positive rate of SNCG expression in adjacent normal tissues was $23.33 \%$ (7/30), whereas the positive rate of SNCG in OSCC tissues was $64.89 \%$ (61/94). Differences between these groups were statistically significant $(\mathrm{p}<0.05)$.

Expression of SNCG and analysis of clinical parameters. Associations of SNCG expression with clinicopathological characteristics, including age, sex, ethnicity, degree of differentiation, clinical stage, and lymph node metastasis, are shown in Table 3. Differences between SNCG expression and degree of differentiation were statistically significant $(p>0.05)$. Nevertheless, differences between SNCG expression and other clinical parameters, including age, sex, ethnicity, clinical stage, and lymph node metastasis were not statistically significant $(\mathrm{p}>0.05)$.

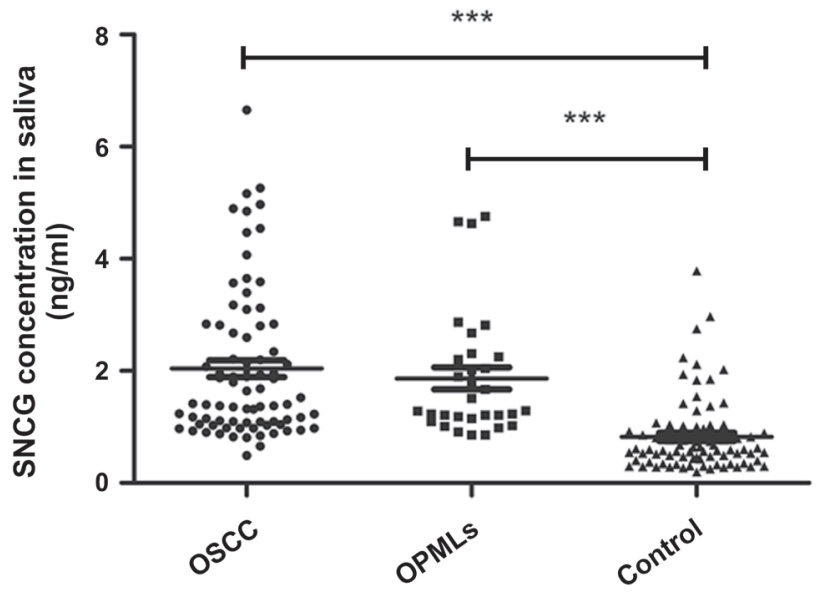

Figure 1. Comparison of the salivary SNCG levels between OSCC, precancerous lesions, and healthy control groups. Each dot represents the SNCG level of each individual subject and the horizontal line represents mean value. The statistical significance is shown: ${ }^{\star *} \mathrm{p}<0.0001$.

Table 1. Expression of salivary SNCG levels in OSCC, precancerous lesions, and healthy control groups.

\begin{tabular}{lccc}
\hline Variables & $\begin{array}{c}\text { Cases } \\
(\mathbf{n})\end{array}$ & $\begin{array}{c}\text { Mean concentration in cases } \\
(\mathbf{n g} / \mathbf{m l})\end{array}$ & p-value \\
\hline OSCC & 79 & $2.041 \pm 1.331$ & $0.436^{\mathrm{a}}$ \\
OPMLs & 31 & $1.865 \pm 1.105$ & $<0.001^{\mathrm{b}}$ \\
Control & 80 & $0.825 \pm 0.668$ & $<0.001^{\mathrm{c}}$ \\
\hline
\end{tabular}

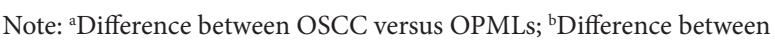
OPMLs versus control; 'Difference between OSCC versus control; OSCC, oral squamous cell carcinoma; OPMLs, oral premalignant lesions.

Table 2. Associations between salivary SNCG levels and clinicopathological variables.

\begin{tabular}{|c|c|c|c|}
\hline Variables & $\begin{array}{c}\text { Cases } \\
(\mathbf{n})\end{array}$ & $\begin{array}{l}\text { Mean concentration in cases } \\
(\mathbf{n g} / \mathrm{ml})\end{array}$ & p-value \\
\hline \multicolumn{4}{|l|}{ Age } \\
\hline$<50$ & 15 & $1.905 \pm 1.200$ & \multirow{2}{*}{$0.661^{\mathrm{a}}$} \\
\hline$\geq 50$ & 64 & $2.074 \pm 1.366$ & \\
\hline \multicolumn{4}{|l|}{ Sex } \\
\hline Male & 46 & $1.915 \pm 1.196$ & \multirow{2}{*}{$0.322^{\mathrm{a}}$} \\
\hline Female & 33 & $2.218 \pm 1.499$ & \\
\hline \multicolumn{4}{|l|}{ Ethnicity } \\
\hline Minority & 15 & $2.486 \pm 1.774$ & \multirow{2}{*}{$0.271^{\mathrm{a}}$} \\
\hline Han & 64 & $1.937 \pm 1.198$ & \\
\hline \multicolumn{4}{|l|}{ Differentiation } \\
\hline Well & 61 & $1.802 \pm 1.104$ & \multirow{2}{*}{$0.022^{\mathrm{a}}$} \\
\hline Moderate, poor & 18 & $2.855 \pm 1.707$ & \\
\hline \multicolumn{4}{|l|}{ Clinical stages } \\
\hline $\mathrm{I}+\mathrm{II}$ & 35 & $2.208 \pm 1.400$ & \multirow{2}{*}{$0.937^{\mathrm{a}}$} \\
\hline III+IV & 44 & $2.052 \pm 1.289$ & \\
\hline \multicolumn{4}{|l|}{ Lymph node status } \\
\hline Negative & 34 & $2.029 \pm 1.329$ & \multirow{2}{*}{$0.941^{\mathrm{a}}$} \\
\hline Positive & 45 & $2.052 \pm 1.346$ & \\
\hline
\end{tabular}

Note: ${ }^{a}$ Student's test 

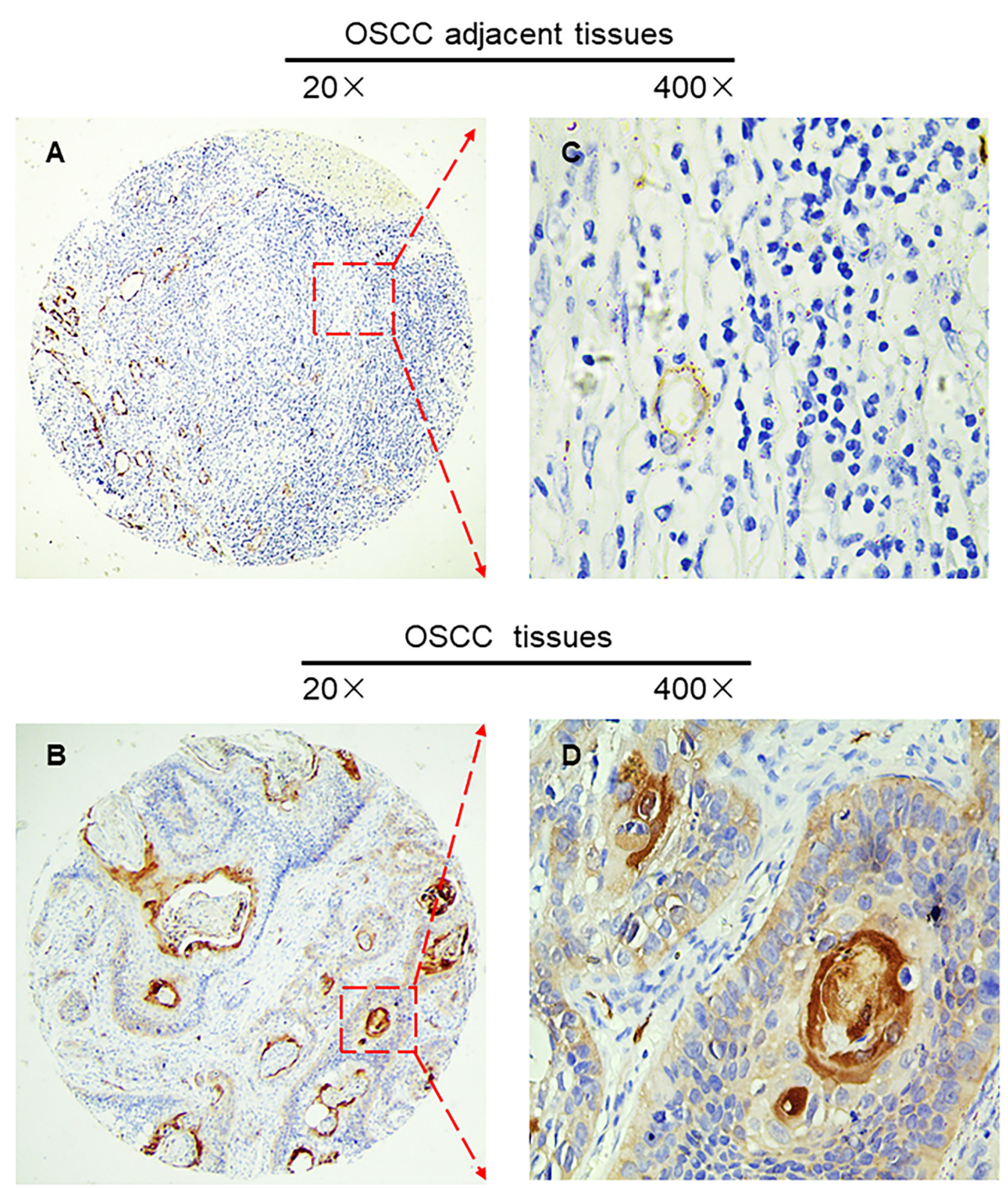

Figure 2. Representative immunohistochemical staining of the SNCG expression in OSCC tissues. A) 20× and C) $400 \times$ staining of a negative sample. B) $20 \times$ and D) $400 \times$ staining of a positive sample. Arrows point to the magnified area.

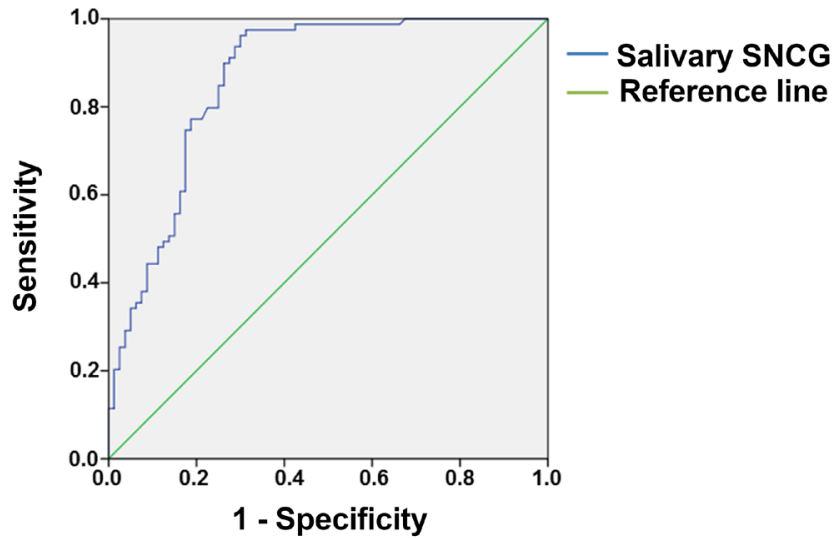

Figure 3. ROC curve of SNCG expression. The area under the curve is 0.865 (95\% CI: $0.808-0.923, p<0.001)$, which indicates that SNCG overexpression in the initial stage has diagnostic value in OSCC.
Diagnostic utility of salivary SNCG. To assess the efficacy of SNCG as potential biomarkers for early diagnosis of OSCC, we performed ROC curve analysis (Figure 3). Based on the distribution of sensitivities and specificities, we chose cut-off thresholds for detecting OSCC. ROC curve analyses revealed that at a cut-off value of $0.8124 \mathrm{ng} / \mathrm{ml}$, the salivary SNCG showed a sensitivity and specificity of $97.5 \%$ and $68.7 \%$, therefore, cases exceeding this value were diagnosed as OSCC. The area under the ROC curves for salivary SNCG was 0.865 (95\%CI: 0.808-0.923).

\section{Discussion}

Salivary biomarkers such as TNF- $\alpha$, MMP-9, IL- $1 \beta$, and IL-8 are involved in many physiological and pathological processes of the human body, such as growth, apoptosis, and 
metastasis of cancer cells; they are, therefore, potential targets in the OSCC diagnosis and biotherapy $[6,11]$. ELISA-based techniques as a population-screening tool are the most costeffective methods for early diagnosis of OSCC [19]. Saliva is composed of organic and inorganic components, desquamated epithelial cells, proteases, and molecules secreted and released by cancer cells. Saliva is abundant and can be easily collected. With the improvement of laboratory techniques, saliva omics has become an effective modality for the prevention, diagnosis, and treatment of oral diseases [11, 15, 19-22]. Furthermore, the detection of salivary markers is innovative, painless, and cost-efficient. With the development of personal prognosis and targeted drug therapy, it might be a potential way to increase the survival rate of OSCC patients.

Synuclein- $\gamma$ is a member of the synuclein family $(\alpha, \beta$, and $\gamma)$ that is associated mainly with cancer and neurodegenerative diseases such as Parkinson's disease and Alzheimer's disease [22]. Abnormal expression of SNCG has been associated with a wide range of human cancers such as cancer of the breast, ovary, cervix, prostate, colon, bladder, liver, lung, stomach, and endometrium and other solid organs [23-24]. In breast tumors, SNCG is highly expressed in advanced stages and appears early in patients with high-risk features, as well as in ovarian cancers. Hypomethylation of $\mathrm{CpG}$ islands in the SNCG gene is responsible for aberrant SNCG expression [25-28]. In prostate cancer, the abundant expression of SNCG is associated with peripheral and lymph node invasion [29]. These findings indicate that SNCG expression may play a role in the severity of disease and can be a potential unfavorable marker for aggressive disease.

In this study, IHC analysis of SNCG expression was conducted using 94 OSCC tissues and 30 samples of tissues adjacent to oral tumor specimens. We correlated SNCG with clinicopathological factors and found that the SNCG expression was positively related to differentiation of OSCC, whereas medium and low degrees of cell differentiation were associated with higher SNCG expression. Schaal et al. reported that in endometrial cancer, the detection of intracellular SNCG protein revealed that the strongest staining pattern became apparent in poorly differentiated grade 3 tumors. Moderate SNCG protein expression was found in grade 2 tumors, while no protein signal could be detected in low-grade EC tumor samples [32].

The expression level of SNCG is related to many factors including differences in genetic status, invasiveness and prognosis, environment, and resistance to radiation or chemotherapy [19]. A previous study reported that the transcription factor Twist1 upregulates SNCG expression through E-boxes in the SNCG promoter in cancer cells [30]. High CA-125 expression was also marginally associated with SNCG expression [31]. Furthermore, hypoxia and acidosis also triggered an increase in nuclear and cytoplasmic SNCG protein levels [32].

Our results suggested that salivary SNCG levels in OSCC were associated with the degree of differentiation. In ovarian
Table 3. Immunohistochemical SNCG expression and its association with clinicopathological variables.

\begin{tabular}{|c|c|c|c|c|c|}
\hline \multirow{2}{*}{ Variables } & \multirow{2}{*}{$\begin{array}{c}\text { Cases } \\
\text { (n) }\end{array}$} & \multicolumn{2}{|c|}{ SNCG expression } & \multirow{2}{*}{${ }^{\mathrm{a}} \chi^{2}$} & \multirow{2}{*}{ p-value } \\
\hline & & Positive (\%) & Negative (\%) & & \\
\hline \multicolumn{6}{|l|}{ Ages } \\
\hline$<50$ & 31 & 17 & 14 & \multirow{2}{*}{2.053} & \multirow{2}{*}{0.152} \\
\hline$\geq 50$ & 63 & 44 & 19 & & \\
\hline \multicolumn{6}{|l|}{ Sex } \\
\hline Male & 71 & 48 & 23 & \multirow{2}{*}{0.937} & \multirow{2}{*}{0.333} \\
\hline Female & 23 & 13 & 10 & & \\
\hline \multicolumn{6}{|l|}{ Differentiation } \\
\hline Well & 45 & 21 & 24 & \multirow{2}{*}{12.589} & \multirow{2}{*}{$<0.001$} \\
\hline Moderate, poor & 49 & 40 & 9 & & \\
\hline \multicolumn{6}{|l|}{ Clinical stages } \\
\hline $\mathrm{I}+\mathrm{II}$ & 74 & 46 & 28 & \multirow{2}{*}{1.139} & \multirow{2}{*}{0.429} \\
\hline $\mathrm{III}+\mathrm{IV}$ & 20 & 15 & 5 & & \\
\hline \multicolumn{6}{|l|}{ Tumour stage } \\
\hline $\mathrm{T} 1+\mathrm{T} 2$ & 82 & 52 & 30 & \multirow{2}{*}{0.617} & \multirow{2}{*}{0.432} \\
\hline $\mathrm{T} 3+\mathrm{T} 4$ & 12 & 9 & 3 & & \\
\hline \multicolumn{6}{|c|}{ Lymph node status } \\
\hline Negative & 28 & 21 & 7 & \multirow{2}{*}{1.788} & \multirow{2}{*}{0.181} \\
\hline Positive & 66 & 40 & 26 & & \\
\hline
\end{tabular}

Note: ${ }^{a}{ }^{2}=$ Chi square

cancer, SNCG expression has a significant association with high-risk clinicopathological factors, such as serous histology, high-grade disease, advanced stage, and suboptimal debulking surgery [26]. In peritoneal cancer, SNCG overexpression is more common in high-grade tumors $(73 \%)$ than in low-grade tumors $(47 \%, \mathrm{p}=0.01)$ [28]. In breast tumors, tumor size, lymph node metastasis, TNM stage, and SNCG expression are significantly associated with overall survival in patients who have received radiotherapy [31]. These associations reveal that SNCG may be a high-risk disease indicator and may play a role in the pathogenesis of disease progression. Furthermore, the prognostic value could be included in further study as some researches showed that there is a probable correlation between SNCG and cancer prognosis $[7,10]$. Interestingly, although the SNCG gene does not have a signal peptide, suggesting it is not a secreted protein, a secreted form of SNCG can be detected in saliva samples from patients with malignant tumors. The potential application of salivary levels of SNCG for diagnosis and prognosis of OSCC warrants further investigation.

In summary, this is the first time to evaluate the value of SNCG expression in the diagnosis of OSCC, to the best of our knowledge. Our study has demonstrated that SNCG is a potential biomarker for the diagnosis of OSCC, and early detection of changes in this protein may be useful for promoting the early detection and early treatment of oral malignant cancer.

Acknowledgments: The present study was supported by grants from the National Natural Science Foundation of China (81560473, 
81560442), and the innovation team Project in key areas of Xinjiang crops (2018CB002). The funding sources had no involvement in the study design, collection, analysis, or interpretation of the data, the writing of the manuscript, or the decision to submit the article for publication. We deeply appreciate Prof. Chengchao Shou and Dr. Caiyun Liu (Peking University Cancer Hospital and Institute) for generously sharing of anti-SNCG MAb no.1 and antiSNCG MAb no.42.

\section{References}

[1] TAJMIRRIAHI N, RAZAVI SM, SHIRANI S, HOMAYOONI S, GASEMZADEH G. Evaluation of metastasis and 5 -year survival in oral squamous cell carcinoma patients in Isfahan (2001-2015). Dent Res J (Isfahan), 2019; 16: 117121.

[2] MEHDI RF, SHEIKH F, KHAN R, FAWAD B, HAQ AU. Survivin Promoter Polymorphism (-31 C/G): A Genetic RiskFactor for Oral Cancer. Asian Pac J Cancer Prev 2019; 20: 1289-1293. https://doi.org/10.31557/APJCP.2019.20.4.1289

[3] SINGH S, GUPTA V, VIJ R, AGGARWAL R, SHARMA $B$ et al. Evaluation of mast cells in oral premalignant and malignant lesions: A histochemical study. Natl J Maxillofac Surg 2018; 9: 184-190. https://doi.org/10.4103/njms. NJMS_49_17

[4] ZHANG L, MENG X, ZHU XW, YANG DC, CHEN R et al. Long non-coding RNAs in Oral squamous cell carcinoma: biologic function, mechanisms and clinical implications. Mol Cancer 2019; 18: 102. https://doi.org/10.1186/s12943019-1021-3

[5] MASCITTI M, ORSINI G, TOSCO V, MONTERUBBIANESI R, BALERCIA A et al. An Overview on Current Noninvasive Diagnostic Devices in Oral Oncology. Front Physiol 2018; 9: 1510. https://doi.org/10.3389/fphys.2018.01510

[6] CHATTOPADHYAY I, PANDA M. Recent trends of saliva omics biomarkers for the diagnosis and treatment of oral cancer. J Oral Biosci 2019, 61: 84-94. https://doi.org/10.1016/j. job.2019.03.002

[7] TIAN L, ZHAO Y, TRUONG MJ, LAGADEC C, BOURETTE RP. Synuclein gamma expression enhances radiation resistance of breast cancer cells. Oncotarget 2018; 9: 27435-27447. https://doi.org/10.18632/oncotarget.25415

[8] LIU C, QU L, ZHAO C, SHOU C. Extracellular gammasynuclein promotes tumor cell motility by activating $\beta 1$ integrin-focal adhesion kinase signaling pathway and increasing matrix metalloproteinase-24, -2 protein secretion. J Exp Clin Cancer Res 2018; 37: 117. https://doi.org/10.1186/s13046018-0783-6

[9] HE K, WANG P. Unregulated long non-coding RNAAK058003 promotes the proliferation, invasion and metastasis of breast cancer by regulating the expression levels of the $\gamma$-synuclein gene. Exp Ther Med 2015; 9: 1727-1732. https:// doi.org/10.3892/etm.2015.2323

[10] LIU C, SHI B, HAO C, WANG Q, LV Q et al. Urine gammasynuclein as a biomarker for the diagnosis of bladder cancer. Oncotarget 2016; 7: 43432-43441. https://doi.org/10.18632/ oncotarget. 9468
[11] FENG Y, LI Q, CHEN J, YI P, XU X et al. Salivary protease spectrum biomarkers of oral cancer. Int J Oral Sci 2019; 11: 7. https://doi.org/10.1038/s41368-018-0032-Z

[12] YANG CM, CHANG HS, CHEN HC, YOU JJ, LIOU HH et al. Low C6orf141 Expression is Significantly Associated with a Poor Prognosis in Patients with Oral Cancer. Sci Rep 2019; 9: 4520. https://doi.org/10.1038/s41598-019-41194-1

[13] G D, NANDAN SRK, KULKARNI PG. Salivary Tumour Necrosis Factor- $\alpha$ as a Biomarker in Oral Leukoplakia and Oral Squamous Cell Carcinoma. Asian Pac J Cancer Prev 2019, 20: 2087-2093. https://doi.org/10.31557/ APJCP.2019.20.7.2087

[14] ZHENG J, SUN L, YUAN W, XU J, YU X et al. Clinical value of Naa10p and CEA levels in saliva and serum for diagnosis of oral squamous cell carcinoma. J Oral Pathol Med 2018, 47: 830-835. https://doi.org/10.1111/jop.12767

[15] LIU C, GUO J, QU L, BING D, MENG L et al. Applications of novel monoclonal antibodies specific for synuclein-gamma in evaluating its levels in sera and cancer tissues from colorectal cancer patients. Cancer Lett 2008; 269: 148-158. https://doi.org/10.1016/j.canlet.2008.04.037

[16] LIU C, DONG B, LU A, QU L, XING X et al. Synuclein gamma predicts poor clinical outcome in colon cancer with normal levels of carcinoembryonic antigen. BMC Cancer 2010; 10: 359. https://doi.org/10.1186/1471-2407-10-359

[17] GREWAL RK, SIRCAR K, BHAT KG, GREWAL DS, TYAGI KK et al. Detection of human papilloma virus-E6/E7 proteins of high-risk human papilloma virus in saliva and lesional tissue of oral squamous cell carcinoma patients using nested multiplex polymerase chain reaction: A comparative study. J Oral Maxillofac Pathol 2018; 22: 318-324. https:// doi.org/10.4103/jomfp.JOMFP_15_18

[18] BU J, BU X, LIU B, CHEN F, CHEN P. Increased Expression of Tissue/Salivary Transgelin mRNA Predicts Poor Prognosis in Patients with Oral Squamous Cell Carcinoma (OSCC). Med Sci Monit 2015, 21: 2275-2281. https://doi. org/10.12659/MSM.893925

[19] SEYEDMAJIDI S, SEYEDMAJIDI M, FOROUGHI R, ZAHEDPASHA A, ZOLFAGHARI SARAVI Z et al. Comparison of Salivary and Serum Soluble CD44 Levels between Patients with Oral SCC and Healthy Controls. Asian Pac J Cancer Prev 2018; 19: 3059-3063. https://doi.org/10.31557/ APJCP.2018.19.11.3059

[20] ABRAO AL, FALCAO DP, DE AMORIM RF, BEZERRA AC, POMBEIRO GA et al. Salivary proteomics: a new adjuvant approach to the early diagnosis of familial juvenile systemic lupus erythematosus. Med Hypotheses 2016; 89: 97-100. https://doi.org/10.1016/j.mehy.2016.02.010

[21] THOMADAKI K, HELMERHORST EJ, TIAN N, SUN X, SIQUEIRA WL et al. Whole-saliva proteolysis and its impact on salivary diagnostics. J Dent Res 2011; 90: 1325-1330. https://doi.org/10.1177/0022034511420721

[22] CHOJNOWSKA S, BARAN T, WILINSKA I, SIENICKA P, CABAJ-WIATER I et al. Human saliva as a diagnostic material. Adv Med Sci 2018; 63: 185-191. https://doi. org/10.1016/j.advms.2017.11.002 
[23] LIU C, QU L, LIAN S, TIAN Z, ZHAO C et al. Unconventional secretion of synuclein- $\gamma$ promotes tumor cell invasion. FEBS J 2014; 281: 5159-5171. https://doi.org/10.1111/ febs. 13055

[24] LIU J, SPENCE MJ, ZHANG YL, JIANG Y, LIU YE et al. Transcriptional suppression of synuclein gamma (SNCG) expression in human breast cancer cells by the growth inhibitory cytokine oncostatin M. Breast Cancer Res Treat 2000; 62: 99-107. https://doi.org/10.1023/a:1006418219012

[25] WU K, WENG Z, TAO Q, LIN G, WU X et al. Stage-specific expression of breast cancer-specific gene gamma-synuclein. Cancer Epidemiol Biomarkers Prev 2003; 12: 920-925.

[26] BRUENING W, GIASSON BI, KLEIN-SZANTO AJ, LEE VM, TROJANOWSKI JQ et al. Synucleins are expressed in the majority of breast and ovarian carcinomas and in preneoplastic lesions of the ovary. Cancer 2000; 88: 2154-2163.

[27] GUPTA A, GODWIN AK, VANDERVEER L, LU A, LIU J. Hypomethylation of the synuclein gamma gene CpG island promotes its aberrant expression in breast carcinoma and ovarian carcinoma. Cancer Res 2003; 63: 664-673.
[28] STROHL A, MORI K, AKERS S, BSHARA W, BUTTIN B et al. Synuclein- $\gamma$ (SNCG) expression in ovarian cancer is associated with high-risk clinicopathologic disease. J Ovarian Res 2016; 9: 75. https://doi.org/10.1186/s13048-016-0281-4

[29] CHEN J, JIAO L, XU C, YU Y, ZHANG Z et al. Neural protein gamma-synuclein interacting with androgen receptor promotes human prostate cancer progression. BMC Cancer 2012; 12: 593. https://doi.org/10.1186/1471-2407-12-593

[30] SHAO T, SONG P, HUA H, ZHANG H, SUN X et al. Gamma synuclein is a novel Twist1 target that promotes TGF- $\beta$ induced cancer cell migration and invasion. Cell Death Dis 2018; 9: 625. https://doi.org/10.1038/s41419-018-0657-z

[31] MIN L, ZHANG C, MA R, LI X, YUAN H et al. Overexpression of synuclein- $\gamma$ predicts lack of benefit from radiotherapy for breast cancer patients. BMC Cancer 2016; 16: 717. https://doi.org/10.1186/s12885-016-2750-y

[32] SCHAAL K, HIRSCHFELD M, BRONSERT P, FULLGRAF $\mathrm{H}$, JAGER $\mathrm{M}$ et al. Alternative splicing of synuclein gamma in endometrial cancer: identification of a novel isoform. Oncotarget 2015; 6: 22553-22563. https://doi.org/10.18632/oncotarget. 4155 